\title{
ЭТНОРЕГИОНАЛЬНЫЕ ПАРТИИ И ИХ ВЛИЯНИЕ НА СТАБИЛЬНОСТЬ ЭТНОФЕДЕРАЛИЗМА
}

\author{
Мария Исобчук \\ Пермский государственный нацииональный исследовательский университет
}

\begin{abstract}
Аннотация
В настоящее время, как в политологии, так и в политике отношение к феномену этнорегиональных партий остается достаточно спорным. С одной стороны, считается, что этнорегиональные партии, являясь основным индикатором сецессионистских настроений, позволяют центральному правительству сформировать устойчивую систему взаимодействия с этническими регионами. С другой стороны, распространено мнение о том, что этнорегиональные партии, напротив, продуцируют сецессионистские процессы. Так или иначе, данный феномен остается актуальным и на сегодняшний момент. В данной статье предпринята попытка переосмыслить феномен этнорегиональных партий при помощи количественного (регрессионного) анализа. Исследование сосредоточено на тестировании влияния на стабильность этнофедерализма следующих параметров партийных систем: фрагментированность и волатильность партийных систем в этнорегиональных автономиях, доля в них этнорегиональных партий, их характер, а также фрагментированность этнорегиональных партий. Влияние данных переменных на стабильность этнофедерализма подтверждено со статистически значимым коэффициентом. В ходе исследования установлено, что на стабильность политической системы влияет не столько наличие или отсутствие этнорегиональных партий, сколько их конфигурация в рамках региональной партийной системы.

Ключевые слова: этнорегиональные партии; этнофедерализм; партийные системы; этнорегиональные автономиии; фрагментированность; волатильность; сецессионизм.
\end{abstract}

Последние несколько десятилетий, исходя из анализа многочисленных политических процессов, происходящих в подавляющем количестве государств, можно охарактеризовать как подъем этнорегиональных партий. Регионализация Европы, административно-территориальные реформы в Индии, Нигерии, Пакистане и других, безусловно, разных политических системах, были не просто сопряжены с расцветом этнорегиональных партий как особого актора, конструирующего описанные процессы, но и, в большей степени, таковым обусловлены. Фактор этнорегиональных партий, в той или иной мере, связан и с такими актуальными тенденциями современной политики, как сецессионизм, национализм, федерализация, конструирование идентичностей и так далее. И, несмотря на тот факт, что

(С) Исобчук М. В., 2018 
еще в 1990-х гг. этнорегиональным партиям предрекали закат (Бирюков С. В., Барсуков А.М., 2010:19), современные политические процессы наглядно доказывают обратное. Так, в прошедшем, 2017 г., этнорегиональные партии сыграли основную роль в сецессионистских процессах в Каталонии, нарастании таковых в Шотландии, Фландрии и других. Все эти факты свидетельствуют о том, что феномен этнорегиональных партий не просто не утратил своего значения в мировой политике, но и актуализировался в еще большей степени.

Между тем феномен этнорегиональных партий, как в политической науке, так и в практической реализации политики, остается весьма спорным. Главенствующие на сегодняшний день теории управления многосоставными государствами ${ }^{1}$ (а феномен этнорегиональных партий имеет проявление только в многосоставных политиях) прямо противоположно характеризуют влияние этнорегиональных партий на стабильность политических систем. Консоциативный подход, подразумевающий инклюзивность этнических групп в политические процессы на основании социальной сегментации (Лейпхарт А., 2007), предусматривает благотворное влияние этнорегиональных партий на политическую стабильность, центростремительный же подход таковое, ввиду целенаправленной гомогенизации статуса политических акторов в этническом разрезе (Горовиц Д. Л., 2015), полностью отрицает. Подобная дихотомия прослеживается и в реальной политике, реализуемой многосоставными государствами. Некоторые из них, например Бельгия, Канада, Индия, не просто не препятствуют генезису этнорегиональных партий, но и нацелены на сотрудничество с таковыми, кооптацию их в национальные политические процессы и институты. Другие, например Танзания,-централизованно запрещают создание этнорегиональных партий. Третьи, к примеру, Эфиопия, Малайзия,-полностью подчиняют этнорегиональные партии национальным в условиях авторитарного режима. Все эти факты свидетельствуют лишь об одном: в настоящее время консенсуса относительно значения и роли этнорегиональных партий в политических процессах не существует. А это значит, что данная исследовательская ниша не теряет своей актуальности. Соответственно, цель данной статьи-проанализировать влияние этнорегиональных партий на стабильность многосоставных политических систем, и этнофедерализма² в целом.

\section{Этнорегиональные партии: концептуализация, классификация, значение}

Большинством исследователей подчеркивается особая роль этнорегиональных партий в конструировании и функционировании системы этнофедерализма.

\footnotetext{
Под многосоставным государством понимается глубоко дифференцированная политическая система ввиду идеологической, национальной, лингвистической, расовой, региональной и т.д. природы его сегментов, при условии, что границы данных сегментов полностью или частично совпадают с линиями политического противостояния.

2 Этнофедерализм - федерализм, в котором, по крайней мере, некоторые, если не все, учредительные единицы федерации - родины, которыми управляют их соответствующие этнические группы.
} 
В условиях полиэтнического государства, в котором институционализированы этнорегиональные автономии, этнорегиональные партии продуцируются самим полиэтническим порядком. Так, Д. Бранчати отмечает, что такие регионы априори обладают уникальными интересами и проблемами, которые должным образом не рассматриваются национальными акторами, что и приводит к генезису этнорегиональных партий (Branchati D., 2007:135).

Между тем проблема концептуализации самого понятия «этнорегиональные партии» существует в академической среде и на сегодняшний день. Если региональный характер партии определить достаточно легко (электоральная конкуренция в масштабах одного региона) (Branchati D., 2007:139), то этнический ее характер не всегда очевиден. Например, Ф. Мюллер-Роммель относит к категории этнорегиональных лишь те партии, которые несут в себе проявление конфликта между центром и периферией и представляют собой «территориальный протест против существующих политических институтов» (Müller-Rommel F., 1998:17-27). Напротив, Д. дэ Винтер, главной дифференцирующей характеристикой этнорегиональных партий называет требования реорганизации национальных государственных структур (De Winter L., 1998:204). Наиболее общеупотребительными характеристиками, определяющими этнорегиональный характер партии, также являются этнический характер и территориальные претензии в пределах установленных региональных границ (Huri T., 1998). В целом, к характеристикам этнорегиональных партий можно отнести следующие моменты (Dandoy R., 2010:207):

- связь с субнациональной территориальной границей;

- идентификация с конкретной этнической общностью;

- членство на основе социокультурных характеристик;

- программная и организационная идентичность и т.д.

В связи с этим, наиболее полное определение этнорегиональных партий можно сформулировать следующим образом: политические партии, представляющие географически сосредоточенные периферийные меньшинства (этнические регионы), которые парируют существующему порядку национального государства, требуя признания их культурной самобытности, структуризации автономии в рамках этнической группы и других преференций на основании особости этнического характера территории, которую они представляют. В дальнейшей работе, под термином «этнорегиональные партии» будут подразумеваться только те партии, которые соответствуют данной совокупности критериев.

Кроме того, говоря об этнорегиональных партиях, нельзя не упомянуть их значительную гетерогенность. Так, Р. Дандой выделяет, по крайней мере, 8 типов этнорегиональных партий (см.табл. 1): 


\section{Классификация этнорегиональных партий.}

Источник: Dandoy R. Ethno-regionalist parties in Europe: a typology // Perspectives on Federalism, Vol. 2, issue 2, 2010

\begin{tabular}{|c|c|c|}
\hline $\begin{array}{c}\text { Категория (характер требо- } \\
\text { ваний) }\end{array}$ & Субкатегория & Требования \\
\hline \multirow{2}{*}{$\begin{array}{l}\text { Протекционистские («мягкие» } \\
\text { требования) }\end{array}$} & Консервативные & Признание, сохранение \\
\hline & Партисипаторционистские & Доступ, участие \\
\hline \multirow{3}{*}{$\begin{array}{l}\text { Децентралистские («умерен- } \\
\text { ные» требования) }\end{array}$} & Автономистские & Власть внутри региона \\
\hline & Федералистские & $\begin{array}{l}\text { Власть в федеративном изме- } \\
\text { рении }\end{array}$ \\
\hline & Конфедералистские & $\begin{array}{l}\text { Власть в конфедеративном из- } \\
\text { мерении }\end{array}$ \\
\hline \multirow{3}{*}{$\begin{array}{l}\text { Сецессионистские («жесткие» } \\
\text { требования) }\end{array}$} & Индепендистские & Независимость \\
\hline & Ирредентистские & $\begin{array}{l}\text { Независимость (в том числе } \\
\text { и присоединение к другому го- } \\
\text { сударству) }\end{array}$ \\
\hline & Раттачистские & $\begin{array}{l}\text { Присоединение к другому госу- } \\
\text { дарству }\end{array}$ \\
\hline
\end{tabular}

Как можно заметить, этнорегиональные партии значимо разнятся по характеру требований, артикулируемых ими. Данный факт, в свою очередь, влияет на характер их взаимодействия с центральным правительством, который нередко сам по себе является конфликтогенным, на роль в партийной системе региона и т.д.

В связи с самим феноменом этнорегиональных партий можно сформулировать, как минимум, следующую их роль в исследуемой проблеме:

1. Политическое выражение этнических, культурных или языковых различий, продуцируемое этнорегиональными партиями, рассматривается как решающая и структурирующая сила партийной системы на региональном уровне (Dandoy R., 2010:197);

2. Этнорегиональные партии-основные политические акторы в условиях этнофедерализма: они агрегируют и артикулируют территориальные притязания конкретной этнической группы, институционализируют их, внося в публичную повестку на уровне региона и принимая решения, а также делиберируют и отстаивают их в процессе взаимодействия с центральным правительством.

3. Наличие этнорегиональных партий напрямую влияет на сохранение и функционирование децентрализации, необходимой при этнофедеративном порядке, и, следовательно, на потенциальное наличие этнического конфликта в рамках этнофедерализма (Cabeza L. et al.,2017:79).

Изучение влияния этнорегиональных партий на конфликтность представлено в работах А. Элиаса и Ф. Тронкони (Elias A., Tronconi F., 2011), Л. Де 
Винтера(De Winter L., 1998), Л. Кабезы (Cabeza L. et al.,2017) и ряда других исследователей. Однако стоит отметить, что зачастую подобные исследования носят скорее дескриптивный характер и являются малоказусными (например, исследования кейса Испании или стран Восточной Европы), а потому несут в себе проблему статистического подтверждения и невозможности экстраполяции результатов ввиду ограниченности кейсов. Именно поэтому, наиболее релевантным методом исследования данной проблемы, отвечающим исследовательским «пробелам» в данной области, является количественный многоказусный анализ, который возможен на основании анализа субнационального проявления деятельности этнорегиональных партий. Кроме того, феномен этнорегиональных партий неотделим от исследования региональной партийной системы в целом, так как именно в условиях констелляции партий в системе и взаимодействия с другими партиями, этнорегиональные партии и принимают свои сущностные характеристики. В данной работе исследование этнорегиональных партий помещено в контекст региональных партийных систем в целом именно по этой причине.

\section{Этнорегиональные партии, партийные системы и этнофедерализм: построение регрессионной модели}

Как было отмечено ранее, целью исследования является выявление параметров региональных партийных систем, детерминирующих устойчивость этнофедерализма. К таковым, прежде всего, относятся структурные параметры партийных систем: фрагментированность и волатильность. Предполагается, что волатильность региональных партийных систем, являясь показателем перманентной динамики перераспределения мандатов в рамках легислатуры, не позволит какой-либо из сторон конфликта монополизировать власть в течение длительного времени, что влияет на интенсивность конфликта. Кроме того, высокая фрагментированность региональной партийной системы указывает на наличие плюрализма в рамках партийной системы, открытый доступ для выражения интересов различных политических сил в рамках легислатуры, ее гибкость и адаптивность по отношению к внешней среде, что также нивелирует интенсивность конфликта. Операционализация данных параметров описана в табл. 2.

Особой значимостью для партийных систем в этнических региональных автономиях обладают этнорегиональные партии. Являясь генеральными артикуляторами этнотерриториальной повестки в автономии и представителями титульной для этнитета этнической группы (Dandoy R., 2010: 196-197), этнорегиональные партии в рамках этнорегиональных автономий являются немаловажной силой, способной влиять на интенсивность конфликта между центром и этнорегиональной периферией. «Этнорегиональность» партии для анализа была операционализирована посредством выявления программной «привязки» партии к определенной этнической группе, а также наличием требований преференций для данной этнической группы в рамках региона. Источником выявления данных параметров являлись программы партий и специализированная исследователь- 
ская литература (Dandoy R., 2010; Elias A., Tronconi F., 2011; Müller-Rommel F., 1998). Безусловно, степень представленности этнорегиональных партий, в зависимости от случая, варьируется, оттого, доля этнорегиональных партий в легислатуре предстает в данной модели значимым параметром.

Следующим важным параметром, связанным с этнорегиональными партиями, в данной модели выступает фрагментированность этнорегиональных партий. Дело в том, что обозначенная выше задача этнорегиональных партий, связанная с взаимодействием с Центром, может быть реализована посредством абсолютно разных стратегий в зависимости от количества этих партий и их взаимодействия. Поэтому данный показатель не менее важен для последующей регрессионной модели. Операционализирован он, в свою очередь, также посредством индекса Эффективного числа партий Г. В. Голосова, немного адаптированным под исследовательскую задачу: в качестве совокупности партий в данном случае представлены не все партии в составе легислатуры, а лишь этнорегиональные (определены посредством предыдущего параметра). Дополнительно, данный параметр был взвешен по отношению к общей доле этнорегиональных партий в легислатуpe, с целью повышения его математической и логической обоснованности. Данная процедура часто значима для количественных исследований ввиду того, что она позволяет не только определить требуемый параметр, но и силу его выражения в конкретных условиях. Так, например, данная математическая процедура характерна для выявления национализации политических партий (Golosov G. V., 2018). Исходя из этого, можно представить формулу операционализации данного параметра следующим образом:

$$
\text { ИФ }{ }_{\text {эРП }}=\sum\left(\frac{1}{1+\frac{P_{1}^{2}}{P_{i}}-P_{i}}\right) * \frac{N_{\text {ЭРП }}}{N_{\text {общ }}}
$$

где

ИФ ${ }_{э р п}-$ индекс фрагментированности этнорегиональных партий в легислатуре;

$\mathrm{P}_{1}$ - доля мандатов наиболее многочисленной партии в легислатуре;

$\mathrm{P}_{\mathrm{i}}$-доля мандатов исчисляемой партии;

$\mathrm{N}_{\text {эрп }}$-сумма мандатов этнорегиональных партий в легислатуре;

$\mathrm{N}_{\text {об̈ }}$-общая сумма мандатов в легислатуре.

Еще одним значимым для модели параметром, имеющим гипотетическую способность влиять на интенсивность конфликта, является наличие сецессионистских партий в легислатуре. Дело в том, что сецессионистские партии являются наиболее радикальными в палитре этнорегиональных партий [6; 206], соответственно, их присутствие в легислатуре ЭРА значимым образом осложняет взаимодействие различных (национальных, региональных, автономистских и др.) политических сил в рамках института. Кроме того, наличие сецессионистских настроений, артикулируемых данными партиями, имеет предписанную конфликтогенность. Наконец, наличие данных партий в региональной легислатуре влияет на выстраивание 
отношений между Центром и этнитетом, опять же, не лучшим образом. Операционализирован данный показатель посредством анализа соответствующей литературы и закодирован дихотомически. Дело в том, что граница между автономистской и сецессионистской партией весьма условна, кроме того, динамична в зависимости от контекста, а потому количественной фиксации не поддается.

В качестве зависимой переменной в анализе выступает интенсивность конфликта, операционализированная посредством Conflict Barometer ${ }^{3}$. В качестве единицы анализа здесь выступает конкретное значение шкалы интенсивности конфликта для каждого из регионов в отдельности.

Таким образом, для выявления влияния дизайна региональных партийных систем на интенсивность этнорегиональных конфликтов были использованы следующие параметры (см. табл. 2):

Таблица 2

\section{Описание переменных}

\begin{tabular}{|c|c|c|}
\hline $\begin{array}{c}\text { Наименование пере- } \\
\text { менной }\end{array}$ & Индекс & Источник данных \\
\hline \multicolumn{3}{|c|}{ Зависимая переменная } \\
\hline $\begin{array}{l}\text { Интенсивность кон- } \\
\text { фликта }\end{array}$ & Conflict Barometer & $\begin{array}{l}\text { Conflict Barometer } \\
\text { (URL: https://www.hiik.de/en/konfliktbarometer/) }\end{array}$ \\
\hline \multicolumn{3}{|c|}{ Независимые переменные } \\
\hline $\begin{array}{l}\text { Фрагментированность } \\
\text { партийной системы }\end{array}$ & $\begin{array}{l}\text { Индекс эффективного } \\
\text { числа партий } \\
\text { Г. Голосова }\end{array}$ & $\begin{array}{l}\text { Электоральная статистика (URL: http:// } \\
\text { psephos.adam-carr.net/about/about.shtml) }\end{array}$ \\
\hline $\begin{array}{l}\text { Волатильность } \\
\text { тийной системы }\end{array}$ & $\begin{array}{l}\text { Индекс волатильности } \\
\text { М. Педерсена }\end{array}$ & $\begin{array}{l}\text { Электоральная статистика (URL: http:// } \\
\text { psephos.adam-carr.net/about/about.shtml) }\end{array}$ \\
\hline $\begin{array}{l}\text { Доля этнорегиональ- } \\
\text { ных партий }\end{array}$ & & $\begin{array}{l}\text { Электоральная статистика (URL: http:// } \\
\text { psephos.adam-carr.net/about/about.shtml) + } \\
\text { источники и литература }\end{array}$ \\
\hline $\begin{array}{l}\text { Фрагментированность } \\
\text { эт н о рег и о на ль ь ы х } \\
\text { партий }\end{array}$ & $\begin{array}{l}\text { Произведение доли эт- } \\
\text { норегиональных партий } \\
\text { на фрагментированность } \\
\text { этнорегиональных пар- } \\
\text { тий (Индекс ЭЧП Г. Го- } \\
\text { лосова) }\end{array}$ & $\begin{array}{l}\text { Электоральная статистика (URL: http:// } \\
\text { psephos.adam-carr.net/about/about.shtml) }\end{array}$ \\
\hline $\begin{array}{l}\text { Наличие сецессио- } \\
\text { нистских партий в ле- } \\
\text { гислатуре }\end{array}$ & $\begin{array}{l}\text { Биноминальная шкала, } \\
\text { где: } \\
\text { «0»-отсутствие сецесси- } \\
\text { онистских партий в леги- } \\
\text { слатуре; } \\
\text { «1»-наличие таковых }\end{array}$ & $\begin{array}{l}\text { Minorities at Risk Organizational Behavior } \\
\text { (URL: http://www.start.umd.edu/data-tools/ } \\
\text { minorities-risk-organizational-behavior/), про- } \\
\text { граммы партий }\end{array}$ \\
\hline
\end{tabular}

Исходя из выборки случаев, определенных посредством понятия «этнофедерализм», были отобраны 60 этнических региональных автономий из 15 этнофедералистских государств. Случаи Нигерии, Швейцарии, Индонезии и Молдавии

3 Conflict Barometer. [online]. URL: https://www.hiik.de/en/konfliktbarometer/ (Accessed: 26.05.2018). 
были исключены ввиду недоступности региональной электоральной статистики, а также отсутствия представленности этнорегиональных партий в региональной легислатуре. В качестве единиц наблюдения выступают электоральные циклы в данных государствах, начиная с 2000 г. Всего в выборке представлено 182 региональных электоральных цикла (см. табл. 3).

Таблица 3

\section{Описание выборки}

\begin{tabular}{|c|c|c|}
\hline Государство & Регион & $\begin{array}{c}\text { Год начала } \\
\text { электорального цикла }\end{array}$ \\
\hline \multirow[t]{2}{*}{ Бельгия } & Валлония & $2004,2009,2014$ \\
\hline & Фландрия & $2004,2009,2014$ \\
\hline \multirow[t]{2}{*}{ Босния и Герцеговина } & Республика Сербская & $2000,2002,2006,2010,2014$ \\
\hline & $\begin{array}{l}\text { Федерация Боснии и Герцего- } \\
\text { вины }\end{array}$ & $2002,2006,2010,2014$ \\
\hline Канада & Квебек & $2003,2007,2008,2012,2014$ \\
\hline \multirow[t]{3}{*}{ Франция } & Корсика & $2005,2010,2015$ \\
\hline & Новая Каледония & 2009,2014 \\
\hline & Полинезия & 2008,2013 \\
\hline \multirow[t]{19}{*}{ Индия } & Андхра Прадеш & $2004,2009,2014$ \\
\hline & Аруначал Прадеш & $2004,2009,2014$ \\
\hline & Ассам & $2001,2006,2011,2016$ \\
\hline & Гоа & $2002,2007,2012,2017$ \\
\hline & Гуджарат & $2002,2007,2012$ \\
\hline & Джамму и Кашмир & $2002,2008,2015$ \\
\hline & Карнатака & $2004,2009,2013$ \\
\hline & Керала & $2001,2006,2011,2016$ \\
\hline & Махараштра & $2004,2009,2014$ \\
\hline & Манипур & $2000,2002,2007,2012$ \\
\hline & Мегхалайя & $2003,2008,2013$ \\
\hline & Мизорам & $2003,2008,2013$ \\
\hline & Нагалэнд & $2003,2008,2013$ \\
\hline & Одиша & $2000,2004,2009,2014$ \\
\hline & Пенджаб & $2002,2007,2012$ \\
\hline & Сикким & $2004,2009,2014$ \\
\hline & Тамил Наду & $2001,2006,2011,2016$ \\
\hline & Трипура & $2003,2008,2013$ \\
\hline & Западная Бенгалия & $2001,2006,2011,2016$ \\
\hline Ирак & Курдистан & $2005,2009,2013$ \\
\hline \multirow[t]{5}{*}{ Италия } & Аоста Вэлли & $2003,2008,2013$ \\
\hline & Фруили Венеция Джулия & $2003,2008,2013$ \\
\hline & Сардиния & 2004, 2009, 2014 \\
\hline & Сицилия & $2001,2006,2008,2012$ \\
\hline & Южный Тироль & $2003,2008,2013$ \\
\hline
\end{tabular}


Окончание табл. 3

\begin{tabular}{|c|c|c|}
\hline Государство & Регион & $\begin{array}{c}\text { Год начала } \\
\text { электорального цикла }\end{array}$ \\
\hline \multirow[t]{4}{*}{ Пакистан } & Балучистан & 2008,2013 \\
\hline & Хибер Патункхва & 2008,2013 \\
\hline & Пенджаб & 2008,2013 \\
\hline & Синдх & 2008,2013 \\
\hline Танзания & Занзибар & $2000,2005,2010,2015$ \\
\hline \multirow[t]{2}{*}{ Никарагуа } & Северный регион & $2002,2006,2010,2014$ \\
\hline & Южный регион & $2002,2006,2010,2014$ \\
\hline Филиппины & Минданао & $2008,2013,2016$ \\
\hline Сербия & Воеводина & $2004,2008,2012,2016$ \\
\hline \multirow[t]{4}{*}{ Испания } & Страна Басков & $2001,2005,2008,2012,2016$ \\
\hline & Каталония & $2003,2006,2010,2012,2015$ \\
\hline & Галисия & $2001,2005,2009,2012,2016$ \\
\hline & Наварра & $2003,2007,2011,2015$ \\
\hline \multirow[t]{3}{*}{ Великобритания } & Северная Ирландия & $2003,2007,2011,2016$ \\
\hline & Шотландия & $2003,2007,2011,2016$ \\
\hline & Уэльс & $2003,2007,2011,2016$ \\
\hline \multirow[t]{7}{*}{ Мьянма } & Качин & 2010,2015 \\
\hline & Каях & 2010,2015 \\
\hline & Чин & 2010,2015 \\
\hline & Мун & 2010,2015 \\
\hline & Рахин & 2010,2015 \\
\hline & Шан & 2010,2015 \\
\hline & Каин & 2010,2015 \\
\hline
\end{tabular}

Таким образом, для регрессионной модели выявлено 5 потенциальных детерминант этнической конфликтности в разрезе этнорегиональных партийных систем. Последующее повествование, в свою очередь, будет сосредоточено на тестировании влияния данных переменных на интенсивность конфликта в этнических региональных автономиях.

\section{Этнорегиональные партии, партийные системы и этнофедерализм: результаты регрессионного анализа}

Ввиду того, что часть переменных (интенсивность конфликта и наличие сецессионистских партий в региональной легислатуре) представлена порядковыми шкалами, для анализа предпочтительнее использование порядковой регрессии. В целом, результаты регрессионного анализа следующие (см. табл. 4): 


\section{Результаты регрессионного анализа}

\begin{tabular}{c|c}
\hline Переменные & Зависимая переменная: интенсивность конфликта \\
\hline Фрагментированность & $-0,410(0,003)^{* *}$ \\
\hline Волатильность & $0,965(0,081)^{*}$ \\
\hline Доля этнорегиональных партий & $-2,776(0,026)^{* *}$ \\
\hline $\begin{array}{c}\text { Фрагментированность } \\
\text { этнорегиональных партий }\end{array}$ & $1,077(0,1)^{*}$ \\
\hline $\begin{array}{c}\text { Наличие сецессионистских пар- } \\
\text { тий в легислатуре }\end{array}$ & $2,020(0,000)^{* * *}$ \\
\hline $\mathrm{N}$ & 182 \\
\hline Нэйджелкерк $\mathrm{R}^{2}$ & 0,285 \\
\hline
\end{tabular}

Примечание: ${ }^{*} p<0.1 ; * * p<0.05 ; * * * p<0.01$

Прежде всего, следует отметить, что все переменные модели обладают статистической значимостью. Кроме того, значение Нэйджелкерк $\mathrm{R}^{2}(0,285)$ подтверждает (учитывая, что регрессия-порядковая) допустимую степень объяснительного потенциала регрессионной модели. На данном этапе влияние каждого из параметров регрессии следует осветить более подробно.

Наиболее значимой детерминантой интенсивности этнического конфликта в этнорегиональной автономии предстает наличие сецессионистских партий в легислатуре. Зависимость интенсивности конфликта от данного параметра является прямой. Таким образом, можно сделать вывод о том, что наличие сецессионистских партий в легислатуре повышает интенсивность конфликта. Действительно, институционализация сепаратистских сил в рамках легислатуры обусловливает сразу несколько фактов: силу выражения сецессионистских настроений среди электората, включение сецессионистской повестки в региональный политический процесс, признание центром наличия сецессионизма в регионе и принятие определенных конфликтогенных действий по нивелированию потенциальной сецессии. Кроме того, сама радикальность сепаратистских партий (в особенности в плане стратегий и методов репрезентации своих целей в публичной сфере) обладает конфликтогенным потенциалом, что также является причиной повышения интенсивности конфликта.

Следующим по статистической значимости предстает параметр фрагментированности партийной системы. Фрагментированность региональной партийной системы повышает доступ различных партий в легислатуру, а также не позволяет сформироваться партийной системе, в которой доминирует только одна из политических сил. Ввиду этого, можно сделать вывод, что высокая степень фрагментированности региональной партийной системы положительно влияет на снижение интенсивности конфликта. 
Достаточно интересны результаты тестирования влияния волатильности региональных партийных систем на интенсивность конфликта: волатильность региональных партийных систем прямо влияет на интенсивность конфликта. Возможно, истоки этой зависимости концентрируются не в самих характеристиках партийных систем, а во взаимодействии Центра и регионов, которое обнаруживает свою значимость в региональном разрезе. Дело в том, что национальный центр заинтересован в наличии в регионе не более одного-двух агентов (партий), с которыми будут выстраиваться отношения по линии «центр-регион». Данные агенты, в свою очередь, должны обладать устойчивым характером в рамках партийной системы региона. Именно поэтому наличие долговременного баланса партий в регионе благотворно влияет на снижение этнического конфликта.

Доля этнорегиональных партий в региональной легислатуре также демонстрирует обратное влияние на интенсивность конфликта. Можно предположить, что высокая доля этнорегиональных партий обусловливает представленность этнорегиональных интересов на региональном уровне. Данный факт, в свою очередь, влияет на снижение ощущения политической депривации этнической группы, что благоприятно влияет на снижение интенсивности конфликта.

Наконец, фрагментированность ЭРП прямо влияет на интенсивность конфликта, то есть большая фрагментированность этнорегиональных партий в легислатуре является причиной высокой степени интенсивности конфликта. Возможно, дело в том, что высокая степень фрагментированности партий иллюстрирует наличие среди этнорегиональных партий сразу несколько весомых политических сил, которые зачастую конкурируют не просто в электоральном разрезе, но и в политическом. В свою очередь, отсутствие консенсуса между этнорегиональными партиями, несет в себе конфликтогенный потенциал и стимулирует, в том числе, рост интенсивности конфликта.

Таким образом, в результате регрессионного анализа было выявлено, что снижение волатильности региональной партийной системы, фрагментированности этнорегиональных партий внутри нее и отсутствие сецессионистских партий благоприятно влияют на снижение интенсивности конфликта. Напротив, повышение фрагментированности региональной партийной системы, а также доли этнорегиональных партий внутри нее стимулируют снижение интенсивности конфликта.

Кроме того, для анализа выявленных зависимостей, следует обратиться к описанию параметров непосредственно статистической модели. Наиболее значимым параметром в данном контексте является соответствие реального и предсказанного значений конфликта. Корреляция между предсказанной категорией отклика и реальной переменной имеет показатель $0,369^{* *}$. Данная корреляция достаточно высока и демонстрирует приемлемую статистическую значимость модели. В целом, распределение значения дельты между двумя данными показателями следующее (табл. 5): 
Дельта между предсказанным и реальным значением конфликта

\begin{tabular}{c|c|l}
\hline $\begin{array}{c}\text { Показатель дельты } \\
\text { между реальным } \\
\text { и предсказанным } \\
\text { значением конфлик- } \\
\text { та }\end{array}$ & Количество случаев & \multicolumn{1}{|c}{ Случаи (по государствам) } \\
\hline 0 & 104 & $\begin{array}{l}\text { Франция, Канада, Босния и Герцеговина, Бельгия, } \\
\text { Италия, Великобритания, Сербия, Испания }\end{array}$ \\
\hline 1 & 24 & Босния и Герцеговина, Бельгия, Пакистан \\
\hline 2 & 14 & Танзания, Филиппины, Индия \\
\hline 3 & 29 & Никарагуа, Индия, Пакистан \\
\hline 4 & 7 & Мьянма, Индия \\
\hline 5 & 3 & Индия \\
\hline
\end{tabular}

Как можно отметить, наибольший показатель дельты конфликта наблюдается в случаях Индии, Мьянмы, Пакистана и Никарагуа. Данный факт можно объяснить тем, что в указанных политических системах механизмы регулирования конфликтов (к примеру, представительство этнических групп, координация конфликта) являются менее институционализированными. Так, в случаях Индии и Никарагуа, межэтнические взаимодействия происходят преимущественно только по партийной линии общенациональных партий. Соответственно, представительство этнических групп в региональной партийной системе остается в зачаточном состоянии и мало соответствует обнаруженной модели. В случаях Мьянмы и Пакистана, а также некоторых индийских северных штатов низкая степень институционализации межэтнических отношений выливается в рост неформальных практик воздействия этнических групп на политику (к примеру, терроризм, массовые нелегальные протесты и др.). И в этом случае каналы взаимодействия региона и центра по партийной линии также затруднены.

Также следует обратиться к динамике предсказанной категории. Предсказанная категория отклика имеет тенденцию «завышать» значение интенсивности конфликта. Например, данная тенденция значимо выражена в случаях автономий Боснии и Герцеговины, Франции, Великобритании (Уэльс), Испании (Каталония), Сербии. Однако для данных случаев характерен высокий уровень внешнего воздействия на регулирование конфликта, что может послужить объяснением данной девиации. Как можно заметить, все перечисленные государства являются членами Европейского союза, членство в котором, в свою очередь, накладывает на них обязательства по сохранению и развитию потенциала миноритарных этнических групп. С другой стороны, в случае большинства автономий Индии (Ассам, Гуджарат, Джамму и Кашмир, Манипур, Мегхалайя, Нагалэнд, Пенджаб и Трипура) показатель предсказанной категории ниже реального коэффициента интенсивности конфликта. Данный факт, возможно, имеет смысл объяснить, исходя из национальной специфики индийской политической и социальной си- 
стемы. Однако объяснением может послужить еще и тот факт, что в данной политической системе высокое значение в межэтническом взаимодействии имеют не только партии, но и другие политические этнические организации, которые имеют интенцию значимого влияния на динамику этнического конфликта.

$$
* * *
$$

Подводя итог работы, прежде всего следует отметить, что каузальная связь между конфигурацией партийной системы, в том числе этнорегиональных партий внутри нее, и стабильностью этнофедерализма подтвердилась. Данный факт свидетельствует о том, что в современных условиях этнорегиональные партии, даже представленные лишь в небольшом количестве и на субнациональном уровне, могут играть значимую роль в поддержании стабильности политической системы, стабильности взаимодействия между Центром и этническими автономиями, а также этническими группами внутри данных автономий.

Из полученных данных, в частности, вытекает тезис о том, что не само наличие институционализированных этнорегиональных политических сил влечет за собой неизбежный конфликт. Дело в том, в какой степени данные силы выражаются, насколько они включены в систему взаимодействия на всех уровнях власти, и насколько данная система является благоприятной.

Кроме того, в ходе анализа представленной регрессионной модели выявлено, что интенцией к влиянию на динамику межэтнического конфликта обладают не только этнорегиональные партии, но и другие акторы. В условиях, когда межэтническое взаимодействие в государстве имеет малую степень институционализации, значимыми акторами межэтнического конфликта являются политические этнические организации другого типа (к примеру, террористические организации, общественные движения). Также на интенсивность конфликта могут влиять и наднациональные политические структуры, и организации. Все данные тезисы свидетельствуют о необходимости более детального анализа влияния этнических организаций, помимо этнорегиональных партий, на динамику этнического конфликта.

\section{Библиографический список}

Бирюков, С.В.\&Барсуков, А.М. (2010)`Этнорегиональные партии как фактор демократизации общеевропейского политического процесса', Регионология, 4, сс. 17-26. [Biryukov, S.V., Barsukov, A.M. (2010)'Ethno-regional parties as factor for democratization of Common European political process' [Etnoregional'nye partii kak faktor demokratizatsii obshcheevropeisko- go politicheskogo protsessa], Regionology, 4, pp. 17-26 (In Russ.)]. Блохина, А.О. (2016)‘Д.Л. Горовиц. Распределение власти в полиэтничных сообществах: три большие проблемы', Политическая наука, 1, сс. 210-223. [Blokhina, A.O. (2016)'Horowitz D. L. Ethnic power sharing: three big problems' [D. L. Gorovits. Raspredelenie vlasti $\mathrm{v}$ polietnichnykh soobshchestvakh: 
tri bol'shie problemy], Political Science, 1, pp. 210-223. (In Russ.)].

Лейпхарт, А. (2007) Демократия в многосоставных обществах. М.: Аспект-Пресс, 287 с. [Lijphart, A. (2007) Democracy in plural societies [Demokratiya $\mathrm{v}$ mnogosostavnykh obshchestvakh]. Moscow: AspektPress Publ., 287 p. (In Russ.)].

Branchati, D. (2007)'The Origins and Strengths of Regional Parties', British Journal of Political Science, 38, pp. 135-159.

Cabeza, L. et al. (2017)‘How National Parties Nationalize Regional', Comparative European Politics, 48 (1), pp. 77-98.

Dandoy, R. (2010)'Ethno-regionalist parties in Europe: a typology', Perspectives on Federalism, 2 (2), pp. 194 220.

De Winter, L. (1998)'Conclusion. A comparative analysis of the electoral, office and policy success of ethnoregionalist parties' in De Winter, L. (ed.) Regionalist parties in Western Europe. London: Routlege, pp. 204247.

Elias, A. and Tronconi, F. (2011)' $F r o m$ protest to power: Autonomist parties in government', Party Politics, 17 (4), pp. 505-524.

Golosov, G.V. (2018)'Party nationalization and the translation of votes into seats under single-member plurality electoral system', Party Politics, 24(2), pp. 118-128, DOI: https://doi. org/10.1177/1354068816642808.

Huri, T. (1998)'Introduction. Ethnoregionalist parties as ethnic entrepreneurs' in De Winter, L. (ed.) Regionalist parties in Western Europe. London: Routlege, pp. 1-16.

Müller-Rommel, F. (1998)'Ethnoregionalist parties in Western Europe. Theoretical considerations and framework of analysis' in De Winter, L. (ed.) Regionalist parties in Western Europe. London: Routlege, pp. 17-25.

\section{Информация об авторе}

Исобчук Мария Вячеславовна - студентка I курса магистратуры, направления «Политология» историко-политологического факультета, ФГБОУ ВО «Пермский государственный национальный исследовательский университет». E-mail: isobchuk.mary@gmail.com (ORCID: W-1549-2017. Researcher ID: 0000-0002-12044313).

Статья принята к печати: 15.10.2018 


\title{
INFLUENCE OF ETHNO-REGIONAL PARTIES ON STABILITY OF ETHNOFEDERALISM
}

\author{
M. V. Isobchuk \\ Perm State University
}

\begin{abstract}
At present, both in political science and in politics, the attitude towards the phenomenon of ethno-regional parties remains quite controversial. On the one hand, it is believed that ethno-regional parties, being the main indicator of secessionist sentiments, make it possible for the central government to form a stable system of interaction with ethnic regions. On the other hand, there is an opinion that ethno-regional parties, on the contrary, produce secessionist processes. In either case, the phenomenon remains relevant for today. In the article, the author makes an attempt to rethink the phenomenon of ethno-regional parties with the help of the quantitative analysis. The research is focused on testing the influence of the following parameters of party systems on the stability of ethnofederalism: fragmentation and volatility of party systems in ethnoregional autonomies, the share of ethno-regional parties in those, their nature, and fragmentation of ethno-regional parties. The influence of these variables on the stability of ethnofederalism was confirmed by a statistically significant coefficient. The study found that the stability of the political system depends not so much on the presence or absence of ethno-regional parties but rather on their configuration within the regional party system.
\end{abstract}

Keywords: ethno-regional party; ethnofederalism; party system; ethno-regional autonomy; fragmentation; volatility; secessionism. 